\title{
Benzodiazepine use in COPD: empirical evidence from Norway
}

\author{
Thomas Halvorsen' \\ Pål E Martinussen² \\ 'SINTEF Technology and Society, \\ Department for Health Research, \\ ${ }^{2}$ Department of Sociology and \\ Political Science, Norwegian \\ University of Science and Technology, \\ Trondheim, Norway
}

\author{
This article was published in the following Dove Press journal: \\ International Journal of COPD \\ 27 August 2015 \\ Number of times this article has been viewed
}

Background: The common comorbidities associated with COPD include, among others, anxiety, depression, and insomnia, for which the typical treatment involves the use of benzodiazepines (BZD). However, these medicines should be used with extra caution among COPD patients, since treatment with traditional BZD may compromise respiratory function.

Aims: This study investigated the use of BZD among persons suffering from COPD by analyzing three relevant indicators: 1) the sum of defined daily doses (DDD); 2) the number of prescribers involved; and 3) the number of different types of BZD used.

Data and methods: The study builds on a linkage of national prescription data and patientadministrative data, which includes all Norwegian drug prescriptions to persons hospitalized with a COPD diagnosis during 2009, amounting to a total of 5,380 observations. Regression techniques were used to identify the patients and the clinical characteristics associated with BZD use.

Results: Of the 5,380 COPD patients treated in hospital during 2009, 3,707 (69\%) were dispensed BZD during the following 12 months. Moreover, they were dispensed on average 197.08 DDD, had 1.22 prescribers, and used 0.98 types of BZD during the year. Women are more likely to use BZD for all levels of BZD use. Overnight planned care not only increases the risk of BZD use (DDD), but also the number of prescribers and the types of BZD in use.

Conclusion: In light of the high levels of BZD prescription found in this study, especially among women, it is recommended that general practitioners, hospital specialists, and others treating COPD patients should aim to acquire a complete picture of their patients' BZD medication before more is prescribed in order to keep the use to a minimum.

Keywords: benzodiazepine use, defined daily doses, number of prescribers, patient and clinical characteristics, Norway, population based study

\section{Introduction}

COPD is a major cause of chronic morbidity and mortality throughout the world. In 2001, COPD was the fifth leading cause of death in high-income countries, and it was also estimated to be a leading cause of disability-adjusted life years. ${ }^{1}$ The common comorbidities associated with COPD include, among others, anxiety, depression, and insomnia, for which the typical treatment involves the use of benzodiazepines (BZD). However, these medicines should be used with extra caution among COPD patients, since treatment with traditional BZD may compromise respiratory function. ${ }^{2,3}$ The potential adverse respiratory effects of BZD in COPD may also be higher in older adults, given their altered pharmacokinetics that increase the BZD half-life. ${ }^{4}$ As such, joint American Thoracic Society/European Respiratory Society guidelines recommend that hypnotics, such as BZD, be avoided in patients with severe COPD. ${ }^{5}$ Yet, BZD are still widely prescribed despite the adverse pulmonary effects that could potentially lead to poor outcomes in the COPD population. ${ }^{3}$ Moreover, overmedication
Correspondence: Pål E Martinussen Department of Sociology and Political Science, Norwegian University of Science and Technology, N-749I Trondheim, Norway

Email paal.martinussen@svt.ntnu.no 
and unnecessary drug use is a risk when the medication regimen becomes too complex. ${ }^{6}$ It is therefore important to understand the scope and nature of BZD use in COPD. Yet, few studies are available that actually investigate the dispensing of these medicines to persons with COPD and the relevant patient and clinical characteristics associated with it. This study thus combines national prescription and patient-administrative data to study the use of BZD in the Norwegian COPD population.

In a review of the research field on anxiety and depression in COPD, Maurer et $\mathrm{al}^{7}$ found that in stable COPD, the prevalence of clinical depression ranged between $10 \%$ and $42 \%$, while that of anxiety ranged between $10 \%$ and $19 \%$. COPD patients are faced with major physical impairment and embarrassing symptoms such as dyspnea and productive cough, and their quality of life is significantly affected through restrictions of daily living and recreational activities, as well as via impairment of social and psychological functioning. ${ }^{8}$ Adding to this, several treatment modalities commonly used in the treatment of COPD can cause nervous system side effects that can put the patient at higher risk for developing psychiatric comorbidities, as they may cause feelings of restlessness, apprehension, anxiety, fear, irritability, and mood changes. ${ }^{9}$

COPD patients are also more likely to suffer from sleep abnormalities, which may take the form of longer latency to sleep onset, more frequent arousals and awakenings, more frequent stage changes, and poorer sleep efficiency than normal individuals. ${ }^{10}$ Over $50 \%$ of COPD patients report a long sleep latency, frequent arousals during the night, and/ or general insomnia. ${ }^{2}$ Insomnia tends to be more prevalent and severe with advanced disease, roughly correlating with the extent of underlying lung disease. ${ }^{10}$ An analysis of a large COPD database revealed that $21.4 \%$ of the listed COPD patients were diagnosed with and treated for insomnia, as compared to only $7.2 \%$ of non-COPD patients. ${ }^{11}$ Sleep disturbance in patients with chronic airflow limitation is found to be consistently associated with reduced quality of life. ${ }^{8}$ The poor sleep quality in COPD patients is due to cough, excess mucous production, and frequent arousals from sleep caused by hypercapnia, as well as to secondary medications used to manage the lung disease. ${ }^{2}$

Hence, from both a psychiatric and sleep deprivation perspective, one should expect that COPD patients comprise a group of high consumers of BZD, but the potential adverse respiratory effects of BZD in COPD suggest the cautious use of these drugs. Estimates that indicate thresholds for increase in risk with low dose treatment would certainly be informative in a presumed high risk population, but such safety data for BZD in patients with COPD are limited. ${ }^{12}$ In a study of the effects of $1.5-2 \mathrm{mg}$ dose lorazepam on respiratory function in COPD, a 20\% decrease in minute ventilation due to decreased tidal volume was found. ${ }^{13}$ Moreover, the results showed a $10 \%-15 \%$ reduction in a number of respiratory muscle functional parameters after a single dose, including negative effects on diaphragmatic endurance. In another study by Cohn et $\mathrm{al}^{14}$ it was noted that a $30 \mathrm{mg}$ dose of flurazepam resulted in a decreased tidal volume in mild COPD patients, and a decrease in oxygen saturation. A third study reported that a single oral dose of diazepam to patients with moderate to severe COPD resulted in a significant decrease in ventilator drive in response to hypercapnia and mouth occlusion. ${ }^{15}$ Studies have also found that $0.25 \mathrm{mg}$ of triazolam significantly decreased the arousal threshold to airway occlusion in both normal subjects and those with severe obstructive sleep apnea syndrome. ${ }^{16,17}$ In a recent study from $2014,{ }^{12}$ which set out to evaluate the safety of BZD and opioids in patients with severe COPD, concurrent BZD and opioids in lower doses $(\leq 0.3$ defined daily doses [DDD]/day) were not associated with increased admissions or mortality, whereas BZD and opioids in higher doses ( $>0.3 \mathrm{DDD} /$ day) might increase mortality.

While several studies have thus described the adverse pulmonary events of BZD in COPD, there is still a lack of research on the use of $\mathrm{BZD}$ among $\mathrm{COPD}$ patients. The present study builds on a linkage of national prescription data and patient-administrative data, which include all Norwegian drug prescriptions to persons hospitalized with a COPD diagnosis during 2009, amounting to a total of 5,380 observations. Regression techniques were used to identify patient and clinical characteristics associated with BZD use. Three relevant indicators of BZD use and consumer behavior were analyzed: 1) the sum of DDD; 2) the number of prescribers involved; and 3) the number of different types of BZD used (ie, different Anatomical Therapeutic Chemical [ATC] classification codes).

\section{Data and methods}

We built our analysis on the assumption that BZD use and consumer behavior among COPD patients can be modeled as a function of patient characteristics (age, sex, and whether the patient died during the period of observation), clinical characteristics (emergency admissions, elective admissions, day treatments, in-hospital treatments, polyclinic consultations, length of stay, and private hospital treatment), and the geographic region where the patient is treated. This can be expressed in a more compact form as Equation 1, where y 
is BZD use/consumer behavior, and $\mathrm{P}, \mathrm{C}$, and $\mathrm{G}$ are vectors that describe the effect of patient characteristics, clinical characteristics, and geography:

$$
\mathrm{y}=f(\mathrm{P}, \mathrm{C}, \mathrm{G})
$$

The empirical basis for the analysis is individual data from the Norwegian Prescription Database (NorPD) that were linked to the Norwegian Patient Register (NPR). Both the NorPD and NPR include a unique personal identification number, which makes it possible to link data from the two registers.

The NorPD contains information about all drugs prescribed (reimbursed or not) and dispensed at pharmacies to individual patients living outside institutions - ie, ambulant care. Unlicensed drugs are also included, but drugs sold over the counter are not recorded in the NorPD. The register records the birth date, month/year of death, sex, and place of residence of the patient, as well as the following information for the prescribed drug: brand name; strength; pharmaceutical form and pack size; number of packs; the World Health Organization's ATC classification codes; the number of DDD; prescription category; reimbursement code; intended use and prescribed dose; dispensing date and price (pharmacy retail price); and the geographic location of the pharmacy.

The NPR covers nearly all inpatient and outpatient hospital care in Norway, and it is owned, funded, and run by the government. Data on the patient's age, sex, residence, hospital, department, diagnosis/diagnoses, and surgical procedure(s), as well as dates of admission, discharge, and procedure(s) are included in the registry.

The information on the use of medicine is generated for each patient by aggregating information on the prescriptions of the relevant drugs during the 12 months following the patient's last hospital discharge in 2009. A total of 5,380 patients where registered with a primary diagnosis of COPD, defined as those with one or more of the following International Classification of Diseases and Related Health Problems (ICD-10) main diagnoses:

- J41: Simple and mucopurulent chronic bronchitis

- J42: Unspecified chronic bronchitis

- J43: Emphysema

- J44: Other chronic obstructive pulmonary disease.

The types of BZD included in the study were clonazepam, diazepam, oxazepam, alprazolam, nitrazepam, flunitrazepam, and midazolam. In addition, we also included the so-called BZD-like hypnotics, commonly termed z-hypnotics. Despite the fact that these types of drugs imply different bindings to the BZD receptor, clinical experience shows that they can have similar effects, and may thus cause the same problems in terms of adverse effects, dependency, abuse, and withdrawal symptoms as those experienced with BZD. ${ }^{18}$ Of the z-hypnotics, only zolpidem and zopiclone are registered for use in Norway, and they are the ones included in this study.

We used number of DDD to measure the volume dispensed of the types of medicine in question. A DDD is defined as the assumed average maintenance dose per day for a drug used for its main indication in adults. The DDD are determined on the basis of evaluation of the international use of the substance in question, bearing in mind that national therapy traditions (indications, dosages) often differ greatly. Each DDD should therefore be regarded as a technical measuring unit. ${ }^{19}$ In addition to consumption, we also included the number of prescribers and the number of different medications (different ATC codes) as outcome measures.

Multivariate regression is used to estimate the relationship between our dependent and independent variables. The distributions of all of our three dependent variables are skewed to the right in its original form. Most COPD patients either use no BZD, or in moderate quantities, and most COPD patients are prescribed BZD from only one or two prescribers, if they are prescribed any at all. Moreover, most COPD patients use only one type of BZD, if at all. There is, however, a substantial group that deviates from this pattern, characterized by the dispensing of higher quantities of DDD, the use of multiple BZD prescribers, and the use of multiple types of BZD. To distinguish between these groups in our analysis, and to avoid the inherent problems associated with skewed distributions, we made use of multinomial logistic regression. All three of our dependent variables are therefore coded into one of four groups, where the base group (the group that all others are compared to) is the one with no BZD dispensing (ie, zero DDD, prescribers, and types of BZD). The coding of the other groups for DDD is as follows: 1) 1-100 DDD; 2) 101-400 DDD; and 3) more than 400 DDD during the year. For the number of prescribers the coding is as follows: 1) 1-2 prescribers; 2) 3-5 prescribers; and 3) more than five prescribers. For BZD types, the coding is as follows: 1) one type; 2) 2-3 types; and 3) more than three types. We choose to have our results reported as the relative risk ratios.

\section{Results}

Of the 5,380 COPD patients treated in hospital during 2009, 3,707 were dispensed BZD during the following 12 months. This is close to $69 \%$ of the patients. Moreover, they were dispensed an average of 197.08 DDD, they had 1.22 prescribers, 
and used 0.98 types of BZD during the year. There were no missing observations for the variables included in our analysis (Table 1).

Tables 2-4 present the results from the regression analysis of BZD use. As could be expected, the patient characteristics are important in explaining BZD use among COPD patients. First of all, male patients had a lower consumption of BZD than did the female patients for all levels of dispensing; they also consulted with fewer prescribers (Table 3) and used fewer medication types than women (Table 4). The finding that BZD are prescribed more frequently to women than to men is also supported by numerous other studies. ${ }^{20-22}$

Age has been found to be a strong predictor of BZD use for the general population, and the same is also found for the COPD patients in our study, although the effect is not significant for the group with more than 400 DDD. ${ }^{21-23}$ The same pattern is also evident for the number of prescribers (Table 3) and types of BDZ (Table 4); however, only the relative risk of using one BZD attains a conventional significance level.

Of the clinical characteristics, elective in-hospital treatment appears to be of particular relevance for the dispensing of BZD. In the model, this variable measures the number of contacts of this type. Each elective in-hospital stay was also associated with the use of more prescribers and medication types. The same relationships hold for daytime acute care and, to some extent, overnight acute care as well, although on a smaller scale, and only for $6+$ prescribers and the group of 2-3 medication types. Length of stay does not have significant effects on BZD use.

Table I Descriptive statistics

\begin{tabular}{|c|c|c|}
\hline Variable & Mean & Standard deviation \\
\hline $\mathrm{DDD}^{\mathrm{a}}$ & 1.279 & 1.068 \\
\hline Number of prescribers ${ }^{a}$ & 0.830 & 0.668 \\
\hline Number of medication types ${ }^{a}$ & 0.939 & 0.757 \\
\hline$M_{e n}^{b}$ & 0.451 & 0.498 \\
\hline Age & 68.736 & I I.087 \\
\hline Death of patient ${ }^{\mathrm{b}}$ & 0.107 & 0.309 \\
\hline Overnight elective care & 0.284 & 0.522 \\
\hline Polyclinic elective care & 0.024 & 0.160 \\
\hline Overnight acute care & 0.069 & 0.260 \\
\hline Daytime acute care & 0.017 & 0.232 \\
\hline Polyclinic acute care & 0.822 & 0.745 \\
\hline Days in treatment & 2.797 & 6.657 \\
\hline Western Norway ${ }^{b}$ & 0.158 & 0.365 \\
\hline Mid-Norway & 0.123 & 0.329 \\
\hline Northern Norway & 0.125 & 0.331 \\
\hline Nonregion/private & 0.031 & 0.174 \\
\hline
\end{tabular}

Notes: a Categorical variables with values 0-3; bdummy variables. Abbreviation: DDD, defined daily doses.
The analysis also uncovers some geographic variations in BZD use. First of all, the results indicate that patients from the northern region are distinguished by a lower prevalence of patients in the group with the highest consumption $(>400$ DDD) compared to the reference group - ie, those in the southeast region. The north also had lower prevalence rates in the group with only one prescriber, but a significantly higher relative risk of belonging to the next group with 2-5 prescribers. The north also had a reduced risk of belonging to the group using 2-3 types of BZD.

\section{Discussion}

BZD are known to cause problems in some patients with obstructive lung disease, and several studies documenting such effects are summed up by George and Bayliff. ${ }^{2}$ Safe pharmacological treatment of insomnia must include consideration for whether the hypnotic could potentially exacerbate the already present breathing problems in COPD patients. ${ }^{3}$ Extra caution is required for persons at increased risk of adverse respiratory effects, such as those with advanced disease. Also, the side effects of cognitive impairment and anterograde amnesia make BZD a poor choice for the elderly COPD population. ${ }^{2,3}$ Given these complications, it gives cause for concern that as much as $69 \%$ of patients treated for COPD also receive BZD. Earlier studies have shown that this is, almost without exception, considerably higher than all other somatic diagnoses and also higher than the average for patients treated at psychiatric hospitals where the similar figure is $52 \%$. $^{24}$

Turning to the covariates, and starting with the patient characteristics, our results are in accordance with the numerous studies that have documented that psychotropic drugs are prescribed more frequently to women than to men. ${ }^{21,22}$ One possible explanation offered for this difference is that it may simply reflect a larger prevalence of depression in females than in males. Also, it may be that women are more likely to seek care for conditions that are treatable by these drugs. ${ }^{21}$ Another possibility is that there is bias within the medical profession that results in women receiving a disproportionate number of prescriptions for psychotropic drugs. According to this hypothesis, physicians may be predisposed to diagnosing neurotic disturbances in women and to medicate women who are experiencing psychological disturbances. ${ }^{20}$

The use of BZD in elderly patients calls for particular attention, since the benefits are the least and the risks the greatest for this age group. ${ }^{25}$ The elderly have a higher risk of dependence and are more sensitive to the adverse effects, such as memory problems, daytime sedation, impaired 
Table 2 Dispensing of BZD measured in DDD for COPD patients (relative risk ratios)

\begin{tabular}{|c|c|c|c|}
\hline Variables & $\begin{array}{l}\text { I-I00 } \\
\text { DDD }\end{array}$ & $\begin{array}{l}101-400 \\
\text { DDD }\end{array}$ & $\begin{array}{l}40 I+ \\
\text { DDD }\end{array}$ \\
\hline Men & $\begin{array}{l}0.626 * * * \\
(0.54 I-0.723)\end{array}$ & $\begin{array}{l}0.622 * * * \\
(0.539-0.717)\end{array}$ & $\begin{array}{l}0.505 * * * \\
(0.426-0.599)\end{array}$ \\
\hline Age & $\begin{array}{l}1.010 * * * \\
(1.003-1.017)\end{array}$ & $\begin{array}{l}1.028 * * * \\
(1.021-1.035)\end{array}$ & $\begin{array}{l}0.997 \\
(0.990-1.005)\end{array}$ \\
\hline Death of patient & $\begin{array}{l}1.63 I^{* * *} \\
(1.289-2.065)\end{array}$ & $\begin{array}{l}0.918 \\
(0.715-1.179)\end{array}$ & $\begin{array}{l}0.436 * * * \\
(0.303-0.626)\end{array}$ \\
\hline Overnight planned care & $\begin{array}{l}\text { I.305*** } \\
(1.074-1.586)\end{array}$ & $\begin{array}{l}1.244 * * \\
(1.021-1.517)\end{array}$ & $\begin{array}{l}1.536 * * * \\
(1.229-1.919)\end{array}$ \\
\hline Polyclinic planned care & $\begin{array}{l}1.225 \\
(0.77|-| .945)\end{array}$ & $\begin{array}{l}1.427 \\
(0.912-2.234)\end{array}$ & $\begin{array}{l}0.853 \\
(0.472-1.542)\end{array}$ \\
\hline Overnight acute care & $\begin{array}{l}1.310 \\
(0.821-2.089)\end{array}$ & $\begin{array}{l}1.347 \\
(0.845-2.147)\end{array}$ & $\begin{array}{l}1.497 \\
(0.884-2.534)\end{array}$ \\
\hline Daytime acute care & $\begin{array}{l}2.74 I^{* * *} \\
(1.402-5.359)\end{array}$ & $\begin{array}{l}2.659 * * * \\
(1.358-5.210)\end{array}$ & $\begin{array}{l}2.377 * * \\
(1.135-4.979)\end{array}$ \\
\hline Polyclinic acute care & $\begin{array}{l}1.059 \\
(0.942-1.191)\end{array}$ & $\begin{array}{l}0.976 \\
(0.863-1.104)\end{array}$ & $\begin{array}{l}0.904 \\
(0.777-1.052)\end{array}$ \\
\hline Days in treatment & $\begin{array}{l}1.002 \\
(0.984-1.020)\end{array}$ & $\begin{array}{l}0.996 \\
(0.978-1.015)\end{array}$ & $\begin{array}{l}1.004 \\
(0.983-1.025)\end{array}$ \\
\hline Western Norway & $\begin{array}{l}0.86 \mathrm{I} \\
(0.70 \mathrm{I}-1.059)\end{array}$ & $\begin{array}{l}0.884 \\
(0.722-1.083)\end{array}$ & $\begin{array}{l}0.933 \\
(0.738-1.178)\end{array}$ \\
\hline Mid-Norway & $\begin{array}{l}0.992 \\
(0.787-1.252)\end{array}$ & $\begin{array}{l}1.121 \\
(0.896-1.404)\end{array}$ & $\begin{array}{l}1.116 \\
(0.860-1.448)\end{array}$ \\
\hline Northern Norway & $\begin{array}{l}0.950 \\
(0.765-1.181)\end{array}$ & $\begin{array}{l}0.868 \\
(0.697-|.08|)\end{array}$ & $\begin{array}{l}0.591 * * * \\
(0.443-0.787)\end{array}$ \\
\hline Nonregion/private & $\begin{array}{l}0.852 \\
(0.470-1.544)\end{array}$ & $\begin{array}{l}1.017 \\
(0.567-1.825)\end{array}$ & $\begin{array}{l}0.605 \\
(0.315-1.159)\end{array}$ \\
\hline Constant & $\begin{array}{l}0.438 * * * \\
(0.268-0.7 \mid 4)\end{array}$ & $\begin{array}{l}0.155 * * * \\
(0.0937-0.256)\end{array}$ & $\begin{array}{l}0.888 \\
(0.509-1.550)\end{array}$ \\
\hline Observations & 5,380 & 5,380 & 5,380 \\
\hline
\end{tabular}

Notes: These values all represent relative risk rations with $95 \%$ confidence intervals in parentheses. $* * P<0.05 ; * * * P<0.01$.

Abbreviations: BZD, benzodiazepines; DDD, defined daily doses.

coordination, and increased risks of motor vehicle accidents, falls, hip fractures, and dementia. ${ }^{26-28}$

It has been documented that many patients are first introduced to BZD during hospitalization. ${ }^{29}$ Typically, BZD initiation may result from short-term insomnia, which may again be due to various aspects associated with hospitalization, such as the effects of illness, new medications, and environmental factors, including noise and disruption of usual sleeping schedules and anxiety. ${ }^{30}$ While the association between hospitalization and BZD initiation has been well explored, we have found few other studies that have linked BZD use to type and frequency of hospitalization. In our study, BZD use was first and foremost related to elective treatment. The most likely explanation is that that the establishment or renewal of long-term BZD treatments will happen in an elective setting, as part of an established medication regimen, while short-term BZD treatments are more likely prescribed in an acute setting. It is, however, a danger that the medication regimen becomes too complex when patients receive prescriptions both in a hospital setting and from their general practitioner. Although we cannot establish with certainty if this is indeed the case here, we can see that the increase in BZD volume is also accompanied by significant increases in both the number of prescribers and the types of BZD used.

Several studies have investigated the effect of length of stay on BZD use, but the relationship remains unclear; some studies have found BZD use to be associated with longer duration of hospitalization, while others have documented no effect of length of stay on the prevalence of BZD use at discharge. ${ }^{30,31}$ Length of stay was not significantly associated with DDD in our study.

Earlier studies have documented geographic variations in the consumption of anxiolytics and z-hypnotics for Norway. ${ }^{24,32}$ The pattern is, however, less clear when studying only COPD patients, but for the northern region, there was still significantly less use of BZD and less combinations of medication types used. 
Table 3 Number of BZD prescribers for COPD patients (relative risk ratios)

\begin{tabular}{|c|c|c|c|}
\hline Variables & I prescriber & 2-5 prescribers & $6+$ prescribers \\
\hline \multirow[t]{2}{*}{ Men } & $0.599 * * *$ & $0.563 * * *$ & $0.636^{*}$ \\
\hline & $(0.531-0.677)$ & $(0.466-0.68 I)$ & $(0.380-1.064)$ \\
\hline \multirow[t]{2}{*}{ Age } & $1.017 * * *$ & 1.002 & 0.982 \\
\hline & $(1.011-1.023)$ & $(0.994-1.011)$ & $(0.96 \mathrm{I}-1.004)$ \\
\hline \multirow[t]{2}{*}{ Death of patient } & $1.197 *$ & $0.518^{* * *}$ & $0.210 * *$ \\
\hline & $(0.968-1.480)$ & $(0.357-0.750)$ & $(0.0472-0.935)$ \\
\hline \multirow[t]{2}{*}{ Overnight planned care } & $1.252^{* * *}$ & $1.616 * * *$ & $2.005^{* *}$ \\
\hline & $(1.056-1.485)$ & $(1.266-2.062)$ & $(1.026-3.916)$ \\
\hline \multirow[t]{2}{*}{ Polyclinic planned care } & 1.319 & 0.875 & $3.33 e-06$ \\
\hline & $(0.888-1.960)$ & $(0.457-1.679)$ & - \\
\hline \multirow[t]{2}{*}{ Overnight acute care } & 1.384 & 1.120 & $3.895 * *$ \\
\hline & $(0.923-2.076)$ & $(0.622-2.017)$ & $(1.294-11.72)$ \\
\hline \multirow[t]{2}{*}{ Daytime acute care } & $2.621^{* * *}$ & $2.549 * *$ & $3.610 * * *$ \\
\hline & $(1.359-5.055)$ & $(1.205-5.392)$ & $(1.684-7.740)$ \\
\hline \multirow[t]{2}{*}{ Polyclinic acute care } & 1.032 & $0.814^{* *}$ & $0.503^{* *}$ \\
\hline & $(0.932-1.143)$ & $(0.676-0.98 \mathrm{I})$ & $(0.254-0.996)$ \\
\hline \multirow[t]{2}{*}{ Days in treatment } & 0.996 & $1.020 *$ & 0.966 \\
\hline & $(0.980-1.012)$ & $(0.999-1.042)$ & $(0.914-1.020)$ \\
\hline \multirow{2}{*}{ Western Norway } & 0.913 & $0.747^{* *}$ & 0.956 \\
\hline & $(0.769-1.082)$ & $(0.559-0.998)$ & $(0.446-2.048)$ \\
\hline \multirow[t]{2}{*}{ Mid-Norway } & 0.987 & $1.468 * * *$ & I.868* \\
\hline & $(0.812-1.200)$ & $(1.108-1.946)$ & $(0.914-3.815)$ \\
\hline \multirow[t]{2}{*}{ Northern Norway } & $0.702 * * *$ & $1.55 I^{* * *}$ & 1.425 \\
\hline & $(0.580-0.848)$ & $(1.196-2.012)$ & $(0.682-2.977)$ \\
\hline \multirow[t]{2}{*}{ Nonregion/private } & 0.878 & 0.772 & 0.420 \\
\hline & $(0.529-1.457)$ & $(0.386-1.542)$ & $(0.0686-2.567)$ \\
\hline \multirow[t]{2}{*}{ Constant } & $0.673 *$ & $0.392^{* * *}$ & $0.194 *$ \\
\hline & $(0.445-1.017)$ & $(0.208-0.738)$ & $(0.0373-1.004)$ \\
\hline Observations & 5,380 & 5,380 & 5,380 \\
\hline
\end{tabular}

Notes: These values all represent relative risk rations with $95 \%$ confidence intervals in parentheses. $* P<0.1 ; * * P<0.05 ; * * * P<0.01 ;-$ Indicates insufficient data. Abbreviation: BZD, benzodiazepines.

There are several limitations in our study. First of all, our data prevented us from controlling for COPD severity. Obviously, the relationship between severity and BZD use is of great concern, since the potential adverse respiratory effects of BZD in COPD is related to severity. Second, our data also lack information on indications for BZD prescriptions, which means that we were unable to distinguish BZD use for insomnia from that related to psychiatric reasons. Third, without established safety data for BZD use in patients with $\mathrm{COPD}$, it becomes difficult to assess the scope of problematic use in our data.

However, in contrast with other similar studies of BZD use in COPD, our study was able to build on patient-administrative data that cover every patient contact with hospital in the country, rather than only a small sample of patients. Thus, we could analyze the whole COPD population, which eliminates common concerns related to representativeness, etc. Moreover, this study adds to the previous research by investigating the role of clinical characteristics for BZD use.

\section{Conclusion}

The high consumption of BZD in COPD found in this study gives cause for concern. The reported effects on respiratory function in other studies suggest that there are significant safety concerns associated with the use of BZD in COPD. ${ }^{12-17}$ Also, adverse effects of BZD on cognitive function suggest that they may not be the best choice for use in elderly COPD patients who may be at increased risk for falls and fractures. ${ }^{3}$ There is clearly a need for further studies to identify the causes of these elevated levels of BZD dispensing and to find alternative treatment strategies to address the sleep abnormalities, anxiety, and depression that follow from the exacerbation of this disease, without exposing the patients to the risks associated with the BZD. Future research would be well advised to take advantage of the possibilities that lie in the increased access to person-identifiable health registers to systematically address these research issues.

Given the unclear role of BZD in the management of refractory breathlessness, this study supports the suggestion that BZD should not be the first-line treatment for 
Table 4 Number of different types of BZD prescribed to COPD patients (relative risk ratios)

\begin{tabular}{|c|c|c|c|}
\hline Variables & I type of BZD & 2-3 types of BZD & $4+$ types of BZD \\
\hline \multirow[t]{2}{*}{ Men } & $0.67 I^{* * * *}$ & $0.462 * * *$ & 0.674 \\
\hline & $(0.59 \mathrm{I}-0.76 \mathrm{I})$ & $(0.397-0.538)$ & $(0.367-1.240)$ \\
\hline \multirow[t]{2}{*}{ Age } & $1.019 * * *$ & $1.006 *$ & $0.976 *$ \\
\hline & $(1.013-1.025)$ & $(0.999-1.013)$ & $(0.95 \mathrm{I}-1.002)$ \\
\hline \multirow[t]{2}{*}{ Death of patient } & 1.015 & 1.137 & 0.351 \\
\hline & $(0.812-1.269)$ & $(0.883-1.464)$ & $(0.0769-1.605)$ \\
\hline \multirow[t]{2}{*}{ Overnight planned care } & 1.148 & $1.650 * * *$ & $2.600 * * *$ \\
\hline & $(0.960-1.373)$ & $(1.354-2.011)$ & $(1.369-4.938)$ \\
\hline \multirow[t]{2}{*}{ Polyclinic planned care } & 1.167 & 1.303 & 0.906 \\
\hline & $(0.767-1.776)$ & $(0.819-2.073)$ & $(0.139-5.906)$ \\
\hline \multirow[t]{2}{*}{ Overnight acute care } & $\mathrm{I} .148$ & $1.88 I^{* * * *}$ & $1.20 \mathrm{e}-06$ \\
\hline & $(0.750-1.757)$ & $(1.190-2.974)$ & - \\
\hline \multirow[t]{2}{*}{ Daytime acute care } & $2.722 * * *$ & $2.382 * *$ & $3.396 * * *$ \\
\hline & $(1.408-5.264)$ & $(1.181-4.804)$ & $(1.538-7.502)$ \\
\hline \multirow[t]{2}{*}{ Polyclinic acute care } & 1.015 & 0.914 & $1.310 *$ \\
\hline & $(0.913-1.129)$ & $(0.799-1.045)$ & $(0.967-1.774)$ \\
\hline \multirow[t]{2}{*}{ Days in treatment } & 1.004 & 0.993 & 1.003 \\
\hline & $(0.988-1.021)$ & $(0.975-1.011)$ & $(0.913-1.102)$ \\
\hline \multirow[t]{2}{*}{ Western Norway } & 0.932 & $0.82 I^{*}$ & 0.444 \\
\hline & $(0.780-1.114)$ & $(0.663-1.018)$ & $(0.154-1.28 I)$ \\
\hline \multirow[t]{2}{*}{ Mid-Norway } & 1.053 & 1.126 & 0.786 \\
\hline & $(0.860-1.289)$ & $(0.891-1.423)$ & $(0.297-2.075)$ \\
\hline \multirow[t]{2}{*}{ Northern Norway } & 0.898 & $0.705 * * *$ & 0.821 \\
\hline & $(0.742-1.087)$ & $(0.554-0.898)$ & $(0.335-2.014)$ \\
\hline \multirow[t]{2}{*}{ Nonregion/private } & 0.871 & 0.782 & 0.583 \\
\hline & $(0.514-1.476)$ & $(0.437-1.400)$ & - \\
\hline \multirow{2}{*}{ Constant } & $0.464 * * *$ & $0.653^{*}$ & $0.120 * *$ \\
\hline & $(0.30 I-0.714)$ & $(0.394-1.08 I)$ & $(0.0202-0.712)$ \\
\hline Observations & 5,380 & 5,380 & 5,380 \\
\hline
\end{tabular}

Notes: These values all represent relative risk rations with $95 \%$ confidence intervals in parentheses. $* P<0.10 ; * * P<0.05 ; * * * P<0.0$ I; - Indicates insufficient data. Abbreviation: BZD, benzodiazepines.

breathlessness in those with respiratory failure. In light of the high levels of BZD prescription found in this study, especially among women, it is recommended that general practitioners, hospital specialists, and others treating COPD patients should aim to acquire a complete picture of their patients' BZD medication before more is prescribed in order to keep the use to a minimum.

\section{Acknowledgment}

The article is based on research funded by the Norwegian Research Council (grant number 196 373).

\section{Disclosure}

The authors report no conflicts of interest in this work.

\section{References}

1. Lopez AD, Mathers CD, Ezzati M, Jamison DT, Murray CJ. Global and regional burden of disease and risk factors, 2001: systematic analysis of population health data. Lancet. 2006;367(9524):1747-1757.

2. George CF, BayliffCD. Management of insomnia in patients with chronic obstructive pulmonary disease. Drugs. 2003;63(4):379-387.
3. Roth T. Hypnotic use for insomnia management in chronic obstructive pulmonary disease. Sleep Med. 2009;10(1):19-25.

4. Vozoris NT, Fischer HD, Wang X, et al. Benzodiazepine use among older adults with chronic obstructive pulmonary disease: a populationbased cohort study. Drugs Aging. 2013;30(3):183-192.

5. Celli BR, MacNee W; ATS/ERS Task Force. Standards for the diagnosis and treatment of patients with COPD: a summary of the ATS/ ERS position paper. Eur Respir J. 2004;23(6):932-946.

6. Frazier SC. Health outcomes and polypharmacy in elderly individuals: an integrated literature review. J Gerontol Nurs. 2005;31(9):4-11.

7. Maurer J, Rebbapragada V, Borson S, et al; ACCP Workshop Panel on Anxiety and Depression in COPD. Anxiety and depression in COPD: current understanding, unanswered questions, and research needs. Chest. 2008;134(4 Suppl):43S-56S.

8. van Manen JG, Bindels PJ, IJzermans CJ, van der Zee JS, Bottema BJ, Schadé E. Prevalence of comorbidity in patients with a chronic airway obstruction and controls over the age of 40.J Clin Epidemiol. 2001;54(3): 287-293.

9. Putman-Casdorph H, McCrone S. Chronic obstructive pulmonary disease, anxiety, and depression: state of the science. Heart Lung. 2009;38(1): 34-47.

10. Douglas N. Chronic obstructive pulmonary disease. In: Kryger M, Roth T, Dement WC, editors. Principles and Practice of Sleep Medicine. Philadelphia, PA: WB Saunders; 2000:965-973.

11. Vallarino CR, Mini L. Prevalence of insomnia in patients with chronic obstructive pulmonary disease in a large database. Value Health. $2005 ; 8: 322$. 
12. Ekström MP, Bornefalk-Hermansson A, Abernethy AP, Currow DC. Safety of benzodiazepines and opioids in very severe respiratory disease: national prospective study. BMJ. 2014;348:g445.

13. Jolly E, Aguirre L, Jorge E, Luna C. [Acute effect of lorazepam on respiratory muscles in stable patients with chronic obstructive pulmonary disease]. Medicina (B Aires). 1996;56(5 Pt 1):472-478. Spanish.

14. Cohn MA, Morris DD, Juan D. Effects of estazolam and flurazepam on cardiopulmonary function in patients with chronic obstructive pulmonary disease. Drug Saf. 1992;7(2):152-158.

15. Beaupré A, Soucy R, Phillips R, Bourgouin J. Respiratory center output following zopiclone or diazepam administration in patients with pulmonary disease. Respiration. 1988;54(4):235-240.

16. Berry RB, McCasland CR, Light RW. The effect of triazolam on the arousal response to airway occlusion during sleep in normal subjects. Am Rev Respir Dis. 1992;146(5 Pt 1):1256-1260.

17. Berry RB, Kouchi K, Bower J, Prosise G, Light RW. Triazolam in patients with obstructive sleep apnea. Am J Respir Crit Care Med. 1995; 151(2 Pt 1):450-454.

18. Sandvik P. Finnes det fornuftig bruk av benzodiazepiner? Utposten. 2008;37:14-18. Norwegian.

19. Sakshaug S, Strøm H, Blix HS, Litleskare I, Rønning M, Granum T. Drug Consumption in Norway 2007-2011. A Statistical Presentation of the Drug Consumption in Norway during the Years 2007-2011 Based on Sales Data from Wholesalers. Oslo, Norway: The Norwegian Institute of Public Health; 2012.

20. Morabia A, Fabre J, Dunand JP. The influence of patient and physician gender on prescription of psychotropic drugs. J Clin Epidemiol. 1992; 45(2):111-116

21. Kassam A, Patten SB. Hypnotic use in a population-based sample of over thirty-five thousand interviewed Canadians. Popul Health Metr. 2006; $4: 15$.

22. Demyttenaere K, Bonnewyn A, Bruffaerts R, et al. Clinical factors influencing the prescription of antidepressants and benzodiazepines: results from the European study of the epidemiology of mental disorders (ESEMeD). J Affect Disord. 2008;110(1-2):84-93.
23. Halvorsen T, Martinussen PE. The geography of chronic obstructive pulmonary disease: a population-based study of Norway. Soc Sci Med. 2014;111:25-34.

24. Haugan T, Halvorsen T, Martinussen PE. Bruk av Vanedannende Legemidler i Norge; $i$ Befolkning Generelt, Og Blant Pasienter Utskrevet Fra Sykehus. Trondheim, Norway: SINTEF; 2011. Norwegian.

25. Bain KT. Management of chronic insomnia in elderly persons. Am J Geriatr Pharmacother. 2006;4(2):168-192.

26. Allain H, Bentué-Ferrer D, Polard E, Akwa Y, Patat A. Postural instability and consequent falls and hip fractures associated with use of hypnotics in the elderly: a comparative review. Drugs Aging. 2005;22(9): 749-765.

27. Bogunovic OJ, Greenfield SF. Practical geriatrics: Use of benzodiazepines among elderly patients. Psychiatr Serv. 2004;55(3):233-235.

28. Billioti de Gage S, Bégaud B, Bazin F, et al. Benzodiazepine use and risk of dementia: prospective population based study. BMJ. 2012;345: e6231.

29. Stuffken R, van Hulten RP, Heerdink ER, Movig KL, Egberts AC. The impact of hospitalisation on the initiation and long-term use of benzodiazepines. Eur J Clin Pharmacol. 2005;61(4):291-295.

30. Bell CM, Fischer HD, Gill SS, et al. Initiation of benzodiazepines in the elderly after hospitalization. J Gen Intern Med. 2007;22(7): 1024-1029.

31. Lagnaoui R, Moore N, Longy-Boursier M, Baumevieille M, Bégaud B. Benzodiazepine use in patients hospitalized in a department of internal medicine: frequency and clinical correlates. Pharmacoepidemiol Drug Saf. 2001;10(6):531-535.

32. Rønning M, Berg C, Furu K, et al. Reseptregisteret 2005-2009. Tema: Vanedannende Legemidler. Nydalen, Norway: Folkehelseinstituttet; 2010:2. Norwegian.
International Journal of COPD

\section{Publish your work in this journal}

The International Journal of COPD is an international, peer-reviewed journal of therapeutics and pharmacology focusing on concise rapid reporting of clinical studies and reviews in COPD. Special focus is given to the pathophysiological processes underlying the disease, intervention programs, patient focused education, and self management protocols.

\section{Dovepress}

This journal is indexed on PubMed Central, MedLine and CAS. The manuscript management system is completely online and includes a very quick and fair peer-review system, which is all easy to use. Visit http://www.dovepress.com/testimonials.php to read real quotes from published authors. 